ISSN 1808-3765

\title{
RESPOSTA PRODUTIVA DO FEIJOEIRO COMUM A DIFERENTES MANEJOS DE IRRIGAÇÃO
}

\author{
MANOEL TEIXEIRA DE FARIA ${ }^{1}$; JOSÉ EDUARDO PITELLI TURCO ${ }^{2}$; EDEMO \\ JOÃO FERNANDES ${ }^{3}$ e ANA PAULA PIRES MACIEL GUIRRA ${ }^{4}$ \\ ${ }^{1}$ Departamento de Engenharia Rural, Faculdade de Ciências Agrárias e Veterinária, Universidades Estadual \\ Paulista, Câmpus Jaboticabal, Jaboticabal-SP, fariamt@bol.com.br \\ ${ }^{2}$ Departamento de Engenharia Rural, Faculdade de Ciências Agrárias e Veterinária, Universidades Estadual \\ Paulista, Câmpus Jaboticabal, Jaboticabal-SP,jepturco@fcav.unesp.br \\ ${ }^{3}$ Departamento de Engenharia Rural, Faculdade de Ciências Agrárias e Veterinária, Universidades Estadual \\ Paulista, Câmpus Jaboticabal, Jaboticabal-SP, ejfernan@fcav.unesp.br \\ ${ }^{4}$ Departamento de Engenharia Rural, Faculdade de Ciências Agrárias e Veterinária, Universidades Estadual \\ Paulista, Câmpus Jaboticabal, Jaboticabal-SP, anappmg_irrig@yahoo.com.br
}

\section{RESUMO}

Este trabalho foi realizado com o objetivo de analisar o manejo mais adequado para a obtenção de maior produtividade para a cultura do feijoeiro grupo carioca, cultivar pérola. O experimento foi conduzido na Área Demonstrativa e Experimental de Irrigação (ADEI) da FCAV/UNESP, Câmpus de Jaboticabal-SP. Foram definidos quatro tratamentos: T1- irrigação com base na $\mathrm{ET}_{0}$ estimada pelo método do Tanque Classe A; T2 - irrigações baseadas em leituras de tensiômetros instalados nas profundidades de 0,20 e $0,40 \mathrm{~m}$; T3 - irrigações efetuadas com base na $\mathrm{ET}_{0}$ estimada pelo método de Penman-Monteith e T4 - testemunha. Os resultados foram submetidos à análise de variância. Para a comparação das médias, foi utilizado o teste de Tukey, a 5\% de probabilidade. O tratamento T3 teve menor lâmina de água aplicada do que os tratamentos T1 e T2, e também menor produtividade. Conclui-se que os tratamentos irrigados com maior frequência apresentaram maior produção de grãos.

PALAVRAS-CHAVE: Phaseolus vulgaris, eficiência do uso da água, água no solo.

\section{FARIA, M. T. DE; TURCO, J. E. P.; EDEMO, J. F.; GUIRRA, A. P. P. M. COMMON BEAN PRODUCTIVE RESPONSE BY DIFFERENT IRRIGATION MANAGEMENT}

\section{ABSTRACT}

The objective of this work was to analyze the most appropriate management to achieve higher productivity for carioca beans (phaseolus vulgaris) and pearl cultivar. The research was developed in the Demonstrative and Experimental Area of Irrigation (ADEI) of FCAV/UNESP, Campus of Jaboticabal, SP. Four treatments were used: T1- irrigation with base in ETo estimated by the method of Class A pan ; T2- irrigations based on tensiometers installed at 0.20 $\mathrm{m}$ and $0.40 \mathrm{~m}$ of depth; T3- irrigations carried out with base in ETo estimated by the PenmanMonteith method and T4- witness. The results were submitted to variance analysis. To compare the average Turkey test was used at 5\% of probability. The treatment T3 had smaller applied water depth than the treatments $\mathrm{T} 1$ and $\mathrm{T} 2$, and also smaller productivity. The conclusion is that the treatments irrigated with larger frequency showed higher production of grains. 
KEYWORDS: Phaseolus vulgaris, water use efficiency, soil water

\section{INTRODUÇÃO}

$\mathrm{Na}$ agricultura irrigada, a decisão sobre o momento apropriado e a quantidade adequada de água a ser aplicada muitas vezes são baseadas em conceito prático do agricultor, acarretando o déficit ou excesso hídrico para a cultura. Devido ao crescimento populacional, o consumo de água vem aumentando, reduzindo assim sua disponibilidade, exigindo procedimentos para racionalização, principalmente no uso agrícola. Portanto, o conhecimento da evapotranspiração é fundamental para determinar as reais necessidades de água para a cultura.

Para Fernandes \& Turco (2003), o conhecimento do consumo de água nos diversos estádios ou etapas de desenvolvimento das plantas permite irrigação mais racional, de acordo com a exigência da cultura. Para a irrigação dar bons resultados, deve ser bem quantificada, pois aplicação de lâminas de água insuficientes repõem água somente nas camadas superficiais do solo, não umedecendo toda a zona das raízes. Por outro lado, irrigações excessivas proporcionam perda de água e nutrientes, além de favorecer o aparecimento de microorganismos patogênicos, podendo prejudicar as raízes por falta de arejamento em casos de solos com drenagem deficiente.

Como a produção agrícola é dependente de vários fatores, tais como água, nutrientes e luz, em que a água é o fator mais limitante da produtividade, assim, torna-se necessário satisfazer as necessidades hídricas das culturas. Isto pode ser conseguido na medida em que a dotação hídrica seja função somente das necessidades da planta, ou seja, o solo deve receber a mesma quantidade de água que perdeu pela evaporação de sua superfície livre e pela transpiração do vegetal (Fernandes \& Turco, 2003).

A cultura do feijão concentra elevada porcentagem do sistema radicular na camada superficial do solo, refletindo-se em alta sensibilidade ao déficit hídrico. Em função disso, o adequado desenvolvimento das plantas está associado à distribuição regular das chuvas ou ao eficiente uso da água de irrigação (Carlesso et al., 2007).

Bons rendimentos de grãos têm sido obtidos quando são mantidas baixas tensões de água no solo. Para tanto, baseando-se na cultura do feijoeiro, são necessárias irrigações frequentes, que não são recomendadas porque aumentam os custos de produção e as perdas de água por evaporação, além de favorecerem a ocorrência de doenças. Desta maneira, deve-se adequar o manejo da irrigação para se alcançar a produtividade ótima econômica, que é, frequentemente, menor que a produtividade máxima potencial (Moreira et al., 1999).

Uma estratégia para reduzir o consumo de água é o gerenciamento da irrigação, considerando possíveis ocorrências de déficits hídricos. Para que esta gestão aperfeiçoe esses benefícios, os níveis de tensão de água no solo e, consequentemente, o estresse a que as plantas serão submetidas entre as irrigações, deverão ser adequadamente controlados. Em geral, o estresse hídrico afeta a produtividade das culturas de maneira variada, pois elas apresentam diferentes e complexos mecanismos de reação a pouca disponibilidade de água (FAO, 2002). Porém, sob condições limitadas de suprimento de água, as plantas adaptam-se ao estresse hídrico, podendo produzir satisfatoriamente com menos água.

A determinação da evapotranspiração é um problema compartilhado por várias ciências que estudam o sistema solo-planta-atmosfera. Devido à necessidade de se conhecer a perda de água pelas superfícies vegetadas, vários pesquisadores desenvolveram métodos de estimativa da evapotranspiração. Uma maneira muito utilizada de obter a evapotranspiração de referência (ETo) é por meio de métodos de estimativa. Sendo que muitos têm aceitação 
quase que unânime, porém o método de Penman-Monteith parametrizado pela FAO é considerado como padrão, enquanto outros são bastante criticados e, muitas vezes, desprezados (Silva, 2011). Nenhum dos que usam dados meteorológicos é universalmente adequado para todas as condições climáticas, sem um ajuste local ou regional (Turco et al., 2008).

Pavani et al. (2008), avaliando o manejo da irrigação na cultura do feijoeiro cultivar pérola em sistemas plantio direto e convencional, em Jaboticabal-SP, observaram que o manejo da irrigação baseado no método do Tanque Classe A proporcionou condições físicohídricas no sistema solo-planta que resultaram em maior eficiência de uso da água pela cultura em relação ao manejo de irrigação por tensiometria.

A demanda total do feijoeiro, estimada com base na evaporação do Tanque Classe A, superestimou em $11 \%$ a demanda determinada por tensiometria, em sistema de plantio convencional (Nascimento et al., 2001).

Com este trabalho, o objetivo foi avaliar qual dos três métodos de manejo de irrigação (tensiometria, Tanque Classe A e Penman-Monteith) proporcionou maior produtividade para a cultura do feijoeiro de inverno.

\section{MATERIAL E MÉTODOS}

O experimento foi conduzido na Área Demonstrativa e Experimental de Irrigação (ADEI), da FCAV/UNESP, Câmpus de Jaboticabal, SP, cujas coordenadas geográficas são: latitude $21^{\circ} 14^{\prime} 48^{\prime}$ ' S, longitude $48^{\circ} 16^{\prime} 44^{\prime \prime}$ 'W e altitude média de $557 \mathrm{~m}$. De acordo com a classificação de Köppen a região apresenta clima tipo Cwa (subtropical com inverno seco). $\mathrm{O}$ regime de chuvas é bem definido, com uma estação chuvosa de outubro a março e uma estação seca de abril a setembro, com pluviosidade anual média de $1.425 \mathrm{~mm}$. As temperaturas máxima, mínima e média do ar são de aproximadamente $28,9^{\circ} ; 16,8^{\circ} ; 22,2^{\circ}$, a umidade relativa do ar com $70,8 \%$, insolação com o total de $2.585,8$ h e total de 117,5 dias com chuva. Os dados foram obtidos da estação agroclimatológica da FCAV-UNESP Câmpus Jaboticabal-SP, referentes ao período de 1971 a 2000.

O solo do local é um Latossolo Vermelho Eutroférrico, segundo recomendações da Embrapa (1999), a declividade média da área experimental é de 8\% com relevo suave ondulado.

A área total experimental foi de $22.910 \mathrm{~m}^{2}$, divididas em 20 parcelas experimentais sendo $216 \mathrm{~m}^{2}$ para cada parcela e área total útil de $67,2 \mathrm{~m}^{2}$, com 10 linhas de planta e 15 metros cada linha. A semeadura foi realizada em 18 de maio de 2010 (outono), e a emergência de $70 \%$ das plântulas ocorreu 10 dias após a semeadura.

A cultivar de feijão Pérola do grupo carioca, foi semeada mecanicamente, no espaçamento de $0,45 \mathrm{~m}$ entre linhas, com 12 sementes por metro, esperando obter uma população final de 200 mil plantas por hectare.

A adubação foi de $300 \mathrm{~kg} \mathrm{ha}^{-1}$ da formulação 2-20-20 $\left(\mathrm{N}^{-} \mathrm{P}_{2} \mathrm{O}_{5}-\mathrm{K}_{2} \mathrm{O}\right)$ distribuída no sulco de semeadura. Foram realizadas duas adubações de cobertura na razão de $100 \mathrm{~kg} \mathrm{ha}^{-1} \mathrm{de}$ N. A primeira adubação realizada 26 dias após a emergência das plantas, e a segunda adubação efetuada 11 dias após a primeira aplicação.

Para o controle de plantas daninhas, foi aplicado herbicida de pré emergência (trifluralina) na dose de $2,4 \mathrm{~L} \mathrm{ha}^{-1}$.

Para as profundidades de 0,20 e $0,40 \mathrm{~m}$, o potencial matricial da água no solo foi convertido em umidade utilizando a seguinte expressão matemática desenvolvida por Van Genuchten (1980), descrita por Dourado Neto et al. (1995), considerando que, a umidade de capa- 
cidade de campo $\left(\theta_{\mathrm{cc}}\right)$, a tensão da água no solo em $\mathrm{cmH}_{2} \mathrm{O}$ e umidade atual $\left(\theta_{\mathrm{A}}\right)$, foram obtidas diariamente com a tensão da água a partir das leituras dos tensiômetros.

$$
\theta_{c}=\theta_{r}+\frac{\left(\theta_{s}-\theta_{r}\right)}{\left[1+\left(\alpha\left|\psi_{m}\right|\right)^{n}\right]^{m}}
$$

Em que,

$\theta_{\mathrm{C}}$ - umidade atual do solo para um determinado valor de potencial mátrico na camada de solo específica $\mathrm{Z}, \mathrm{cm}^{3} \mathrm{~cm}^{-3}$;

$\theta_{\mathrm{r}}$ - umidade residual do solo, $\mathrm{cm}^{3} \mathrm{~cm}^{-3}$;

$\theta_{\mathrm{S}}-$ umidade do solo na saturação, $\mathrm{cm}^{3} \mathrm{~cm}^{-3}$;

$\alpha, \mathrm{n}, \mathrm{m}$ - constantes de ajuste do modelo;

$\left|\Psi_{\mathrm{m}}\right|$ - módulo do valor do potencial mátrico do solo, cm c.a.

Os valores das características físico-hídricas do solo da área, como valores médios para as camadas de $0-20$ e $0,20-0,40 \mathrm{~m}$ de profundidade, podem ser observados na Tabela 1 .

Tabela 1. Características físico-hídricas médias e constantes da equação de GENUCHTEN para as camadas de $0-0,20$ e $0,20-0,40 \mathrm{~m}$ de profundidade do solo da área experimental

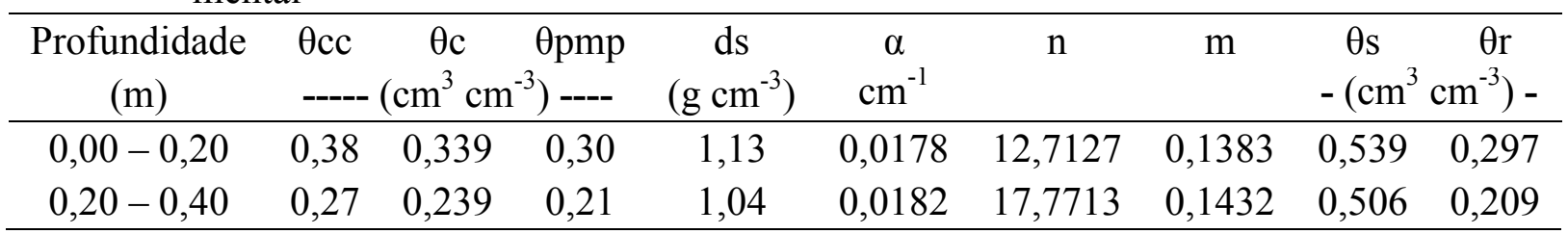

$\theta \mathrm{cc}$ - umidade do solo à capacidade de campo; $\theta \mathrm{c}$ - umidade crítica do solo; $\theta$ pmp - umidade do solo no ponto de murchamento permanente; ds - densidade do solo; $\theta \mathrm{s}$ - umidade do solo saturado; $\theta \mathrm{r}$ - umidade residual do solo; $\alpha, \mathrm{n}$ e $\mathrm{m}$ são as constantes empíricas.

Foram determinadas a capacidade de água disponível no solo (CAD, em $\mathrm{mm}$ ), a água facilmente disponível no solo (AFD, em $\mathrm{mm}$ ) e a reserva de água disponível no solo (RAD, $\mathrm{mm})$ pelas seguintes expressões:

$\mathrm{CAD}=\left(\theta_{\mathrm{CC}}-\theta_{\mathrm{pmp}}\right) \mathrm{Z}$

$\mathrm{AFD}=0,5 \mathrm{CAD}$

$\mathrm{RAD}=(\mathrm{CAD}-\mathrm{AFD})$

Em que:

$\theta_{\mathrm{CC}}$ - umidade do solo $\mathrm{cm}^{3} \mathrm{~cm}^{-3}$ à capacidade de campo (potencial de $-103,32 \mathrm{cmH}_{2} \mathrm{O}$ );

$\theta_{\mathrm{pmp}}$ - umidade do solo $\mathrm{cm}^{3} \mathrm{~cm}^{-3}$ no ponto de murchamento permanente para o potencial mátrico de $-15498.41 \mathrm{cmH}_{2} \mathrm{O}$;

$\mathrm{Z}$ - profundidade efetiva do sistema radicular da cultura (0,3 - 0,4 m) (Pires et al., 2001). 
Utilizou-se o sistema de irrigação por aspersão convencional com aspersores dispostos em 12 x 18 m, com raio de alcance de 16 m e operado com pressão de serviço de 294,0 kPa.

A condução do experimento ocorreu de maio de 2010 a setembro de 2010, em plena estação seca. Os dados climatológicos do período, medidos na estação automatizada instalada na área experimental, são apresentados na Tabela 2.

Tabela 2. Caracterização climática na área experimental durante a condução do experimento

\begin{tabular}{|c|c|c|c|c|c|c|}
\hline & \multicolumn{2}{|c|}{ Temp, média $\left({ }^{\circ} \mathrm{C}\right)$} & \multirow{2}{*}{$\begin{array}{l}\text { UR } \\
(\%)\end{array}$} & \multirow{2}{*}{$\begin{array}{c}\text { Precipitação } \\
(\mathrm{mm})\end{array}$} & \multirow{2}{*}{$\begin{array}{c}\text { Velocidade do vento } \\
\qquad\left(\mathrm{m} \mathrm{s}^{-1}\right)\end{array}$} & \multirow{2}{*}{$\begin{array}{l}\text { Saldo de radiação } \\
\left(\mathrm{MJ} \mathrm{m}^{-2} \mathrm{dia}^{-1}\right)\end{array}$} \\
\hline & Máxima & Mínima & & & & \\
\hline Junho & 28,29 & 9,48 & 56,5 & 0,0 & 0,92 & 11,05 \\
\hline Julho & 29,23 & 10,95 & 51,9 & 0,0 & 1,17 & 10,64 \\
\hline Agosto & 29,13 & 6,07 & 39,9 & 0,0 & 1,24 & 12,50 \\
\hline Média & 28,88 & 8,83 & 55,0 & 0,0 & 1,11 & 11,40 \\
\hline
\end{tabular}

Até a fixação da cultura no campo toda a área foi igualmente irrigada, a partir de então os tratamentos passaram a ser irrigados quando a soma da evapotranspiração da cultura era de aproximadamente $50 \%$ do total de água disponível (CAD) que foi considerado o fator de disponibilidade de água no solo (f). Este fator é um parâmetro que limita a parte da água disponível do solo que a planta pode utilizar sem causar maiores prejuízos à produtividade. Ele também é um fator de segurança que define a sensibilidade da cultura ao défict hídrico. (MANTOVANI et al., 2009). Segundo os mesmos autores, os valores de (f) recomendado para grãos é de 0,4 a 0,6 .

Os tratamentos foram designados da seguinte maneira:

Tratamento T1 - irrigação com base na $\mathrm{ET}_{0}$ estimada pelo método do Tanque Classe $\mathrm{A}\left(\mathrm{ET}_{\mathrm{CCA}}\right)$ por intermédio das seguintes expressões:

$\mathrm{ET}_{0}=\mathrm{ECA} \mathrm{kp}$

$\mathrm{ET}_{\mathrm{CCA}}=\mathrm{ET}_{0} \mathrm{kc}$

Em que:

$\mathrm{ET}_{0}$ - evapotranspiração de referência $\left(\mathrm{mm} \mathrm{dia}^{-1}\right)$;

ECA - evaporação medida no Tanque Classe A $\left(\mathrm{mm} \mathrm{dia}^{-1}\right)$;

kp - coeficiente do tanque obtido em tabela (Pereira,. et al., 1977);

ETC $_{\mathrm{CCA}}$ - evapotranspiração de cultura estimada pelo método do Tanque Classe A ( $\left.\mathrm{mm} \mathrm{dia}^{-1}\right)$; $\mathrm{kc}$ - coeficiente de cultura simplificado (adimensional), estimado diariamente, interpolando os valores recomendados por Allen et al. (2006).

Tratamento T2 ( $\left.\mathbf{T}_{\mathbf{E N S}}\right)$ - irrigações baseadas em leituras de tensiômetros instalados nas profundidades de 0,20 e 0,40 m. A metodologia seguida para a irrigação foi acompanhar a umidade residual diária e convertê-la em lâmina de água armazenada e subtrair da capacidade de água disponível no solo (CAD), irrigando toda vez que essa diferença atingia um valor de aproximadamente $14,2 \mathrm{~mm}$. 
Tratamento $\mathbf{T 3}$ - irrigações efetuadas com base na $\mathrm{ET}_{0}$ estimada pelo método de Penman-Monteith .

Para calcular a evapotranspiração de referência pelo método de Penman-Monteith $\left(\mathrm{ET}_{0 \mathrm{PM}}\right)$, foi utilizada a seguinte expressão (Allen et al., 2006):

$\mathrm{E}^{\prime \prime} \mathrm{IPM}_{\mathrm{MA}}=\frac{0,408 \mathrm{~s}\left(\mathrm{R}_{\mathrm{n}}-\mathrm{G}\right)+\left(\frac{900}{\mathrm{~T}+273}\right) \mathrm{U}_{2}\left(\mathrm{e}_{\mathrm{s}}-\mathrm{e}_{\mathrm{L}}\right)}{\left[\mathrm{s}+\mathrm{O}\left(1+0,34 \mathrm{U}_{2}\right)\right]}$

Em que:

$\mathrm{ET}_{0 \mathrm{PM}}$ - evapotranspiração de referência Penman-Monteith $\left(\mathrm{mm} \mathrm{dia}^{-1}\right)$;

$\mathrm{Rn}$ - radiação líquida medida na superfície de referência $\left(\mathrm{MJ} \mathrm{m}^{-2} \operatorname{dia}^{-1}\right)$;

$\mathrm{G}$ - fluxo de calor do solo ( $\mathrm{MJ} \mathrm{m} \mathrm{mia}^{-2}$ );

$\mathrm{s}$ - inclinação da curva de pressão de vapor $\left(\mathrm{kPa}^{\circ} \mathrm{C}^{-1}\right)$;

$\mathrm{T}$ - temperatura média diária do ar a $2 \mathrm{~m}$ de altura $\left({ }^{\circ} \mathrm{C}\right)$;

$\mathrm{U}_{2}$ - Velocidade média do vento a $2 \mathrm{~m}$ de altura $\left(\mathrm{m} \mathrm{s}^{-1}\right)$;

$\mathrm{e}_{\mathrm{s}}$ - pressão de vapor de saturação $(\mathrm{kPa})$;

$\mathrm{e}_{\mathrm{a}}$ - pressão de vapor real $(\mathrm{kPa})$;

$\mathrm{e}_{\mathrm{s}}-\mathrm{e}_{\mathrm{a}}-$ déficit de pressão de vapor à saturação $(\mathrm{kPa})$;

$\gamma$ - constante psicrométrica $\left(\mathrm{kPa}^{\circ} \mathrm{C}^{-1}\right)$.

A evapotranspiração de cultura $\left(\mathrm{ET}_{\mathrm{CPM}}\right)$ foi estimada multiplicando a $\mathrm{ET}_{0 \mathrm{PM}}$ pelo coeficiente de cultura $(\mathrm{kc})$.

$\mathrm{ET}_{\mathrm{CPM}}=\mathrm{ET}_{\mathrm{OPM}} \mathrm{kc}$

Tratamento T4 - testemunha, irrigada para germinação e estabelecimento da lavoura no campo e uma irrigação por ocasião da adubação de cobertura.

Antes da instalação do experimento no campo, foi realizado um teste de uniformidade do sistema de irrigação onde foi encontrado um coeficiente de uniformidade de Christiansen (CUC) de 81,7\%, um coeficiente de distribuição (CUD) de 74,4\% e uma lâmina média de $23,07 \mathrm{~mm} \mathrm{~h}^{-1}$. Instalaram-se um registro de gaveta e um manômetro na saída de cada linha lateral para regular a pressão. $O$ valor da lâmina de água aplicada em cada irrigação foi determinado pela média das quantidades de água recebidas em oito pluviômetros distribuídos de maneira equidistante dentro de cada parcela.

Baseado na CAD, foi aplicada uma lâmina de $30,0 \mathrm{~mm}$ em todos os tratamentos para começar o manejo da irrigação com o solo na umidade de capacidade de campo.

Ao final do ciclo da cultura, avaliaram-se os seguintes componentes de produtividade: estande final, número médio de vagens produtivas por planta, número médio de grãos por vagem, produtividade de grãos (13\% de umidade) e eficiência da água aplicada (EAA $\mathrm{kg} \mathrm{m}^{-3}$ ).

Foi calculada a eficiência da água aplicada (EAA $\mathrm{kg} \mathrm{m}^{-3}$ ), definida como eficiência de produção, ou seja, a massa de grãos produzida para cada unidade de volume de água evapotranspirada pela cultura durante todo o seu ciclo (Tennakoon \& Hulugalle, 2006). A EAA foi calculada pela razão entre a produtividade de grãos $\left(\mathrm{kg} \mathrm{ha}^{-1}\right)$ e o volume total de água aplicado durante o ciclo da cultura, baseado na ETc. 
Foi utilizado o delineamento estatístico inteiramente casualizado (DIC), e os tratamentos foram submetidos à análise de variância, e as médias comparadas pelo teste de Tukey ou teste $\mathrm{t}$, a $5 \%$ de probabilidade.

\section{RESULTADOS E DISCUSSÃO}

A partir da germinação e estabilização da cultura no campo, foi realizado um estresse hídrico de oito dias, com a finalidade de aumentar a profundidade do sistema radicular, e aos 26 dias após a emergência, aplicou-se uma lâmina de $30 \mathrm{~mm}$ em todos os tratamentos, cuja finalidade foi iniciar o experimento com a mesma condição hídrica do solo (Figura 1). Observa-se, na mesma figura, que todas as vezes que a soma da evapotranspiração da cultura atingia um valor de aproximadamente $14,2 \mathrm{~mm}$, o que representa $50 \%$ da capacidade de água disponível no solo (CAD), na camada de $0-0,40 \mathrm{~m}$ de profundidade, realizou-se a irrigação conforme a necessidade de cada tratamento para elevar a umidade para a da capacidade de campo.
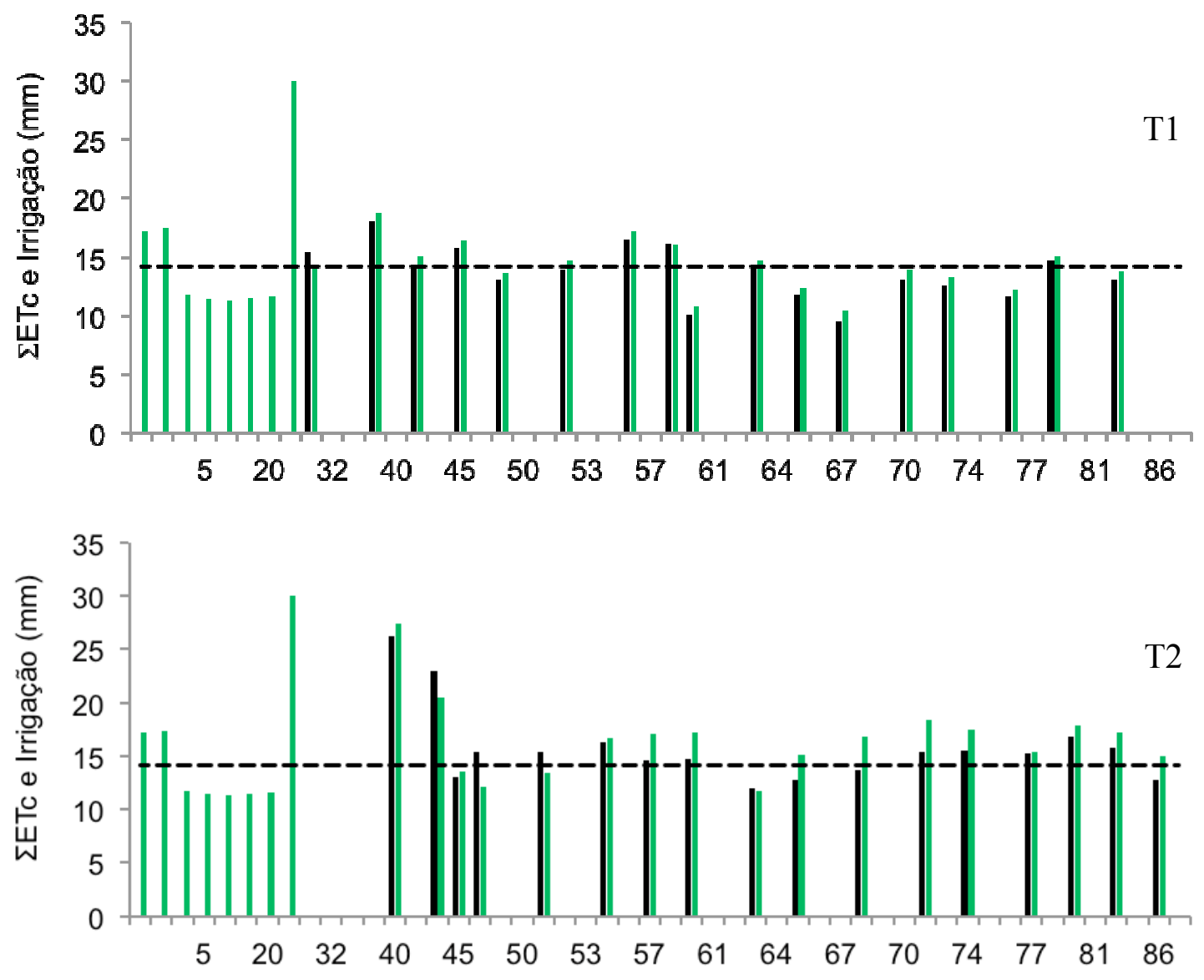


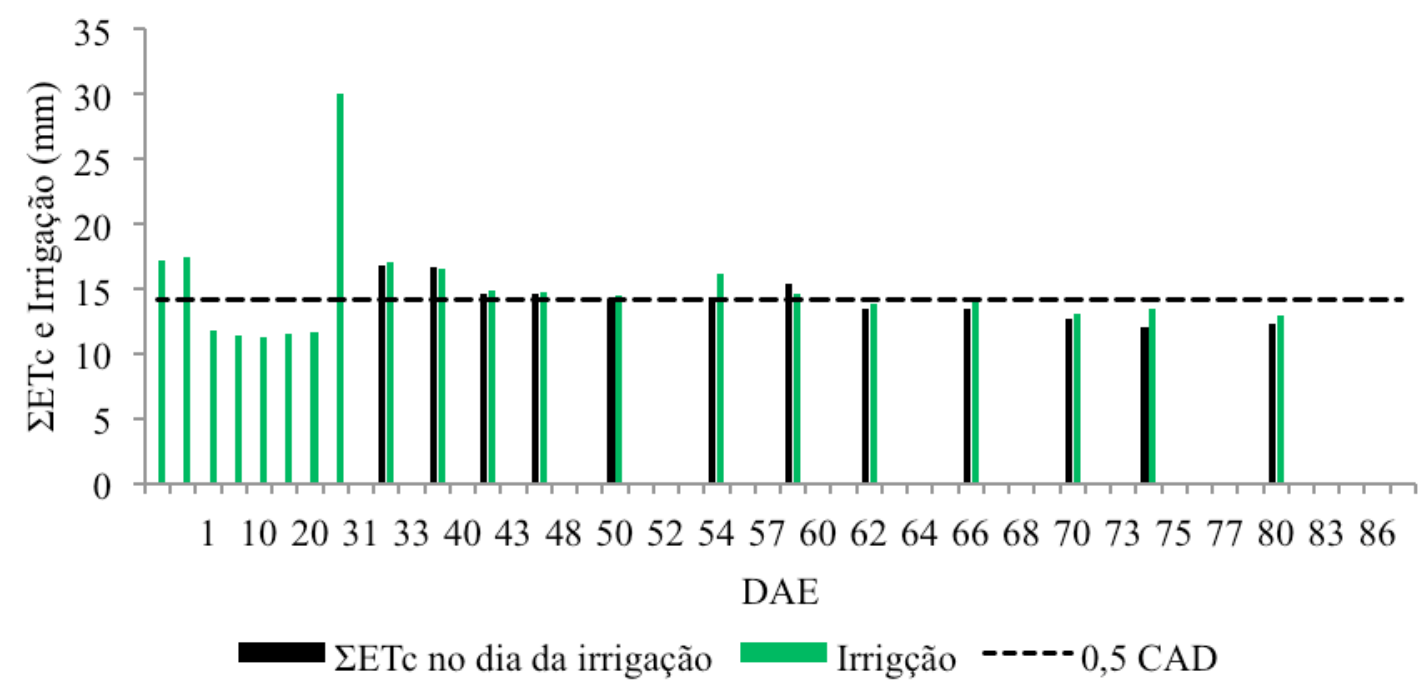

Figura 1. Somatória da evapotranspiração e irrigação no dia em que foi necessário irrigar cada tratamento.

Nota-se, na Figura 2, que os tratamentos receberam, durante todo o desenvolvimento da cultura (plantio a maturação fisiológica), lâminas totais de água de 364,4; 404,9; 297,7 e 145,8 mm, distribuídos em 25; 25; 20 e 9 aplicações, respectivamente, para T1, T2, T3 e T4. Durante a realização do experimento de campo, não houve precipitação (chuva). Pode ser observado também na Figura 2, que os tratamentos T1 e T2 apresentaram maior evapotranspiração, superando a do tratamento $\mathrm{T} 3$ em todo o ciclo da cultura.

\section{Tratamentos}

$\mathrm{T} 1$

$\mathrm{T} 2$

$\mathrm{T} 3$

$\mathrm{T} 4$

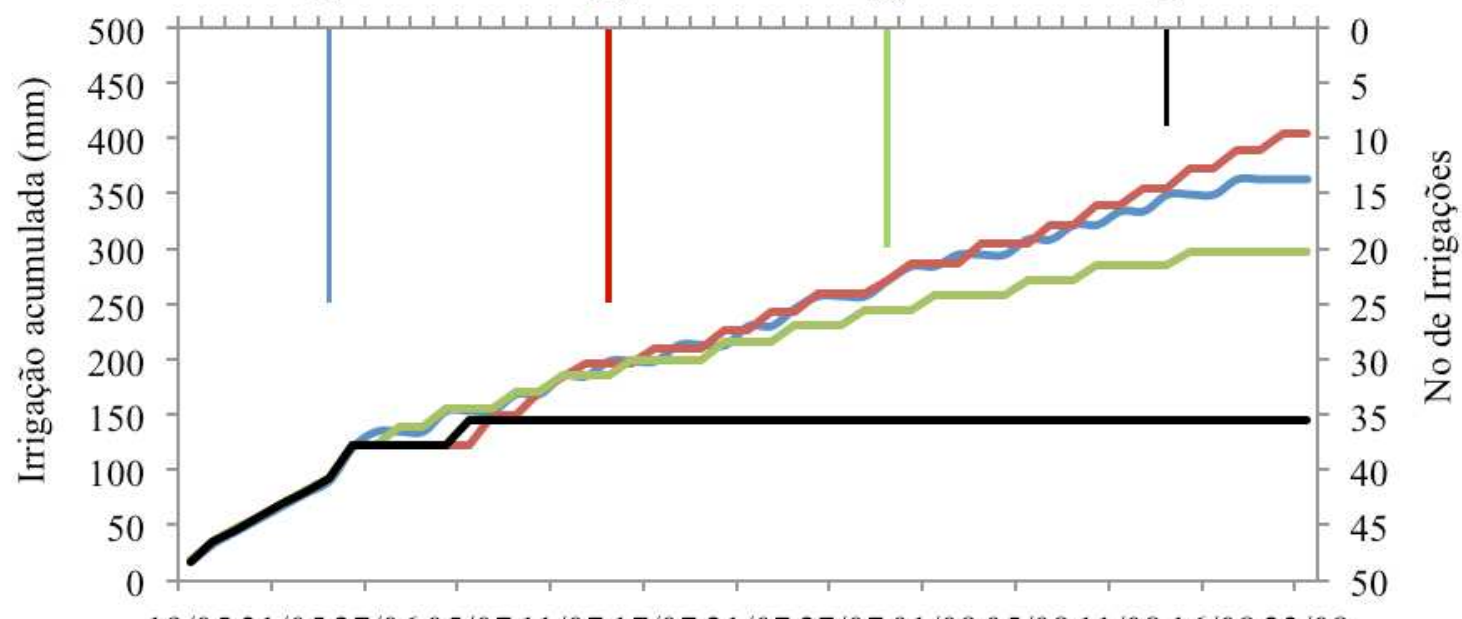

19/05 31/05 27/06 05/07 11/07 17/07 21/07 27/07 01/08 05/08 11/08 16/08 23/08

Data

\section{No Irrigações $\longrightarrow$ TCA (T1) Tens. (T2)}

Figura 2. Irrigação acumulada em cada tratamento com os respectivos números de ocorrências. 
Observa-se, na Tabela 3, que não houve diferença dos fatores de produção estande final, vargem/planta, grãos/vagem e produtividade entre os manejos T1 e T2 (P > 0,05), divergindo de Pavani et al. (2008), que encontraram diferença significativa para os fatores de produção vagem/planta e número médio de grãos/vagem, produtividade e eficiência de uso da água pela cultura, quando compararam os manejos de irrigação por tensiometria e tanque Classe "A" em plantio convencional. O T3 foi diferente de T1 e T2 apenas nas componentes vagens por planta e produtividade, provavelmente devido ao déficit hídrico ocorrido durante o ciclo da cultura. Este déficit ocorreu devido ao método de Penman-Monteith estimar a evapotranspiração da cultura diária menor que os demais métodos. O T4 foi menor do que os demais tratamentos em todos os fatores de produção.

Quando avaliada a eficiência da água aplicada, observa-se, na Tabela 3, que não houve diferença entre os tratamentos T1 e T2, e entre T2 e T3, porém T1 foi mais eficiente que T3, e o tratamento que recebeu irrigação parcial (T4) foi menos eficiente no uso da água aplicada.

Tabela 3. Componentes de produtividade da cultura do feijoeiro e eficiência da água aplicada (EAA).

\begin{tabular}{cccccc}
\hline $\begin{array}{c}\text { Manejo da } \\
\text { Irrigação }\end{array}$ & $\begin{array}{c}\text { Estande } \\
\text { Final }\end{array}$ & $\begin{array}{c}\text { Vagem/ } \\
\text { Planta }\end{array}$ & $\begin{array}{c}\text { Grãos/ } \\
\text { vagem }\end{array}$ & $\begin{array}{c}\text { Prod. } \\
(\mathrm{kg} / \mathrm{ha})\end{array}$ & EAA \\
\hline T1 & $212.500,25 \mathrm{a}$ & $11,25 \mathrm{a}$ & $4,25 \mathrm{a}$ & $2.686,75 \mathrm{a}$ & $0,7375 \mathrm{a}$ \\
T2 & $209.722,50 \mathrm{a}$ & $11,00 \mathrm{a}$ & $4,75 \mathrm{a}$ & $2.935,50 \mathrm{a}$ & $0,7250 \mathrm{ab}$ \\
T3 & $211.111,25 \mathrm{a}$ & $7,75 \mathrm{~b}$ & $4,25 \mathrm{a}$ & $1.808,50 \mathrm{~b}$ & $0,6075 \mathrm{~b}$ \\
T4 & $122.222,25 \mathrm{~b}$ & $5,50 \mathrm{c}$ & $3,05 \mathrm{~b}$ & $382,75 \mathrm{c}$ & $0,2864 \mathrm{c}$ \\
\hline
\end{tabular}

Valores seguidos de letras distintas diferem entre si na mesma coluna, pelo teste de Tukey $(\mathrm{P}<0,05)$.

Analisando-se as Figuras 1 e 2, verifica-se que os tratamentos T1 e T2 foram irrigados com maior frequência e receberam maior lâmina que o tratamento T3, apresentando maior produção de grãos (Figura 3), corroborando Fernandes (2008), que verificou que os tratamentos irrigados com maior frequência apresentaram maior produção de grãos.

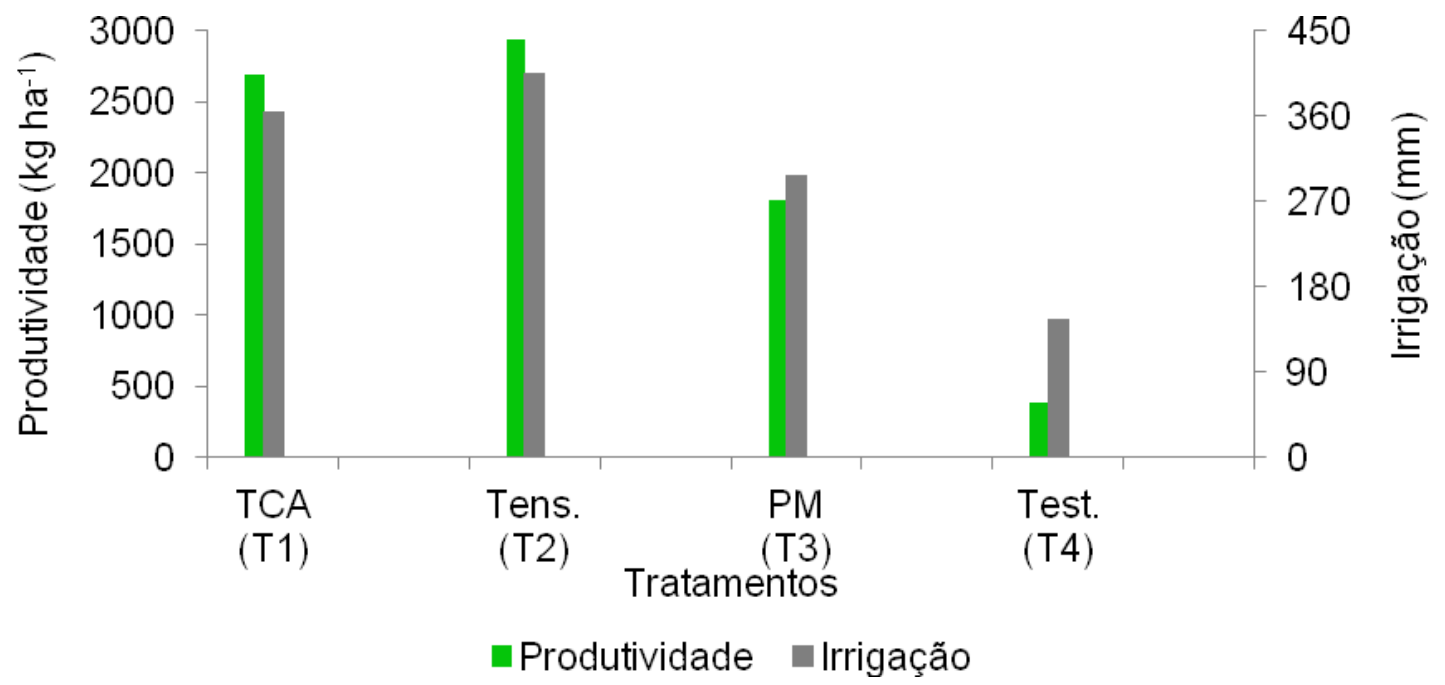

Figura 3. Produtividade da cultura do feijoeiro em função do total de água aplicada durante o ciclo da cultura. 


\section{CONCLUSÕES}

Os resultados deste estudo mostram que para as condições do experimento os métodos de manejo baseados no Tanque Classe "A", Razão de Bowen e Tensiometria proporcionaram melhores condições hídricas à cultura tendo como resposta melhor produtividade em relação ao manejo baseado na estimativa da ETo pelo método de Penman-Monteith.

\section{REFERÊNCIAS BIBLIOGRÁFICAS}

ALLEN, R. G.; PEREIRA, L. S.; RAES, D.; SMITH, M. Evapotranspiración del cultivo Guías para la determinación de los requerimientos de agua de los cultivos. Organización de las Naciones Unidas para la Agricultura y la Alimentación. Roma, 2006.

CARLESSO, R.; JADOSKI, S. O.; MAGGI, M. F. PETRY, M.; WOLSHK, D. Efeito da lâmina de Irrigação na Senescência. Foliar do Feijoeiro. Irriga, Botucatu, v.12, n.4, p.545-546, 2007.

DOURADO NETO, D. Programa SWRC (Version 1.00): Soil-Water Retention Curve (software). Piracicaba: ESALQ; DAVIS: University of Califórnia, 1995.

EMBRAPA. EMPRESA BRASILEIRA DE PESQUISA AGROPECUÁRIA. Sistema brasileiro de classificação de solos. Rio de Janeiro, 2006. 306 p.

ESTAÇÃO AGROCLIMATOLÓGICA. Normais Climatológicas FCAV/UNESP. Disponível em: www.fcav.unesp.br/portal_agromet/mostra_arq_multi.php?arquivo=1. Acesso em: 22 ago. 2011.

FAO. Deficit irrigation practices. (Water Reports, 22). Rome, 2002. 103p.

FERNANDES, E. J. Comparação entre três métodos para estimar lâminas de irrigação. Irriga, Botucatu, v.13, n1, p.36-46, 2008.

FERNANDES, E. J.; TURCO, J. E. P. Evapotranspiração de referência para manejo da irrigação em cultura de soja. Irriga, Botucatu, v.8, n.2, p.132-141, 2003.

MANTOVANI, E. C.; BERNARDO, S.; PALARETTI, L. F. Irrigação: princípios e métodos. 2. ed., atual e. ampl. Viçosa, MG: UFV, 2009. 358p.

MOREIRA, J.A.A.; STONE, L.F.; SILVA, S. C. da; SILVEIRA, P.M. da. Irrigação do feijoeiro no sistema plantio direto. (Embrapa Arroz e Feijão. Circular Técnica, 33). Santo Antônio de Goiás: Embrapa Arroz e Feijão, 1999. 31p.

NASCIMENTO, J. L.; STONE, L. F.; OLIVEIRA, L. F. C. de. Demanda total de água do feijoeiro nos sistemas de plantio convencional e direto. Pesquisa Agropecuária Tropical, v.31, n.2, p.159-161, 2001. 
PAVANI, L. C.; LOPES, A. S.; GALBEIRO, R. B. Manejo da irrigação na cultura do feijoeiro em sistemas plantio direto e convencional. Engenharia Agrícola, Jaboticabal, v.28, n.1, p.12-21, 2008.

PEREIRA, A. R.; VILA NOVA, N. A.; SEDIYAMA, G. C. Evapotranspiração. Piracicaba: FEALQ. 1997.

PIRES, R.C.M.; SAKAI, E.; ARRUDA, F.B.; FOLEGATTI, M.V. Necessidades hídricas das culturas e manejo de irrigação. In: MIRANDA, J.H.; PIRES, R.C.M. Irrigação. Piracicaba: SBEA, 2001. v.1, p.121-94. (Série Engenharia Agrícola).

SILVA, V. J. da; CARVALHO, H. P.; SILVA, C. R. da; CAMARGO, R. de; TEODORO, R. E. F. Desempenho de diferentes métodos de estimativa da evapotranspiração de referência diária em Uberlândia-MG. Bioscience Journal, Uberlândia, v.27, n.1, p.95-101, 2011.

TENNAKOON, S. B.; HULUGALLE, N.R. Impact of crop rotation and minimum tillage on water use efficiency of irrigated cotton in a Vertisol. Irrigation Science, Berlin, v.25, n.1, p.45-52, 2006.

TURCO, J. E. P.; PERECIM, D.; PINTO JR., D. L. Influência da acurácea de instrumentos de medidas na comparação de métodos de estimativa da evapotranspiração de referência. Irriga, Botucatu, v.13, n.1, p.63-80, janeiro-março 2008. 